\title{
Textos multimodais na aula de português: metodologia de leitura
}

\author{
Lucia Teixeira* \\ Karla Faria e Silvia Sousa**
}

\section{Resumo}

O artigo apresenta proposta metodológica para a abordagem de textos multimodais em aulas de língua portuguesa. Considera a multimodalidade um modo de produção de conteúdos próprio das sociedades pós-industriais e discute o conceito a partir da contribuição da semiótica francesa, que propõe uma resolução sincrética para textos que operam com diferentes linguagens. Submetidos a uma estratégia enunciativa, os textos sincréticos não podem ser abordados como uma soma de diferentes códigos em interação, mas como produtos de operações enunciativas que conferem unidade à diversidade. Propõe-se uma metodologia de abordagem de tais textos na escola, por meio de exemplos comentados.

Palavras-chave: Sincretismo. Multimodalidade. Estratégia enunciativa. Semiótica.

\section{Introdução}

Nas chamadas sociedades pós-industriais, vivemos em meio ao excesso, à fragmentação, à dispersão e à variedade. Imersos num mundo de tecnologia, em que os apelos visuais e sonoros são irresistíveis, os jovens da era da cibercultura têm a capacidade de ouvir música, ler mensagens nas redes sociais, falar ao celular e trocar de roupa ao mesmo tempo. Trata-se de uma geração que substituiu o jantar em família, em redor da mesa, pelo lanche solitário no quarto, diante

\footnotetext{
Doutora em Linguística e Semiótica pela USP e atua no Programa de Pós-graduação em Estudos de Linguagem da Universidade Federal Fluminense. E-mail: luciatso@gmail.com

** Doutora em Letras pela UFF e professora do Programa de Pós-graduação em Estudos de Linguagem desta Universidade; Karla Faria (kcafaria@gmail. com) é doutora em Estudos de Linguagem pela UFF. As autoras são pesquisadoras do SeDi-UFF (Grupo de Pesquisa em Semiótica e Discurso da UFF). E-mail: silviamsousa05@gmail.com
}

Data de submissão: jul. 2014 - Data de aceite: ago. 2014 http://dx.doi.org/10.5335/rdes.v10i2.4295 
da tela do tablet, e navega não mais na imaginação que sonha amores impossíveis e carinhos vãos, mas nos sites que invadem suas inquietações e oferecem-lhes às vezes tão pouco, mas tão mais do que lhes pode sugerir o mundo das obrigações e deveres, quando desejam apenas diversão e entretenimento. São meninos e meninas que não mais marcam encontros no bar, mas no instagram, não mais chamam o amigo no telefone de casa, mas se comunicam pelo WhatsApp, mantêm-se conectados em grupos de conversa e seguem e são seguidos no twitter. São moços e moças que compartilham on-line seus momentos, fotos e emoções, em conversas virtuais em que todos se adoram, mandam beijos abreviados e abraços desenhados, encurtam palavras e repartem risadas feitas de letras e carinhas. Expostos nas postagens que compartilham em blogs, são arredios ao desenho caligráfico das letras correndo em páginas de cadernos com cadeados em que se costumava escrever diários. Apressados, comunicam-se em mensagens de recebimento instantâneo, sem paciência para os ultrapassados e-mails, muito menos para bilhetes e cartas.

Esses jovens, que estudam enquanto assistem à MTV ou que trocam o potencial estético e emotivo das telas de cinema pelos filmes da cultura pop que baixam no computador, podem, entretanto, nos ensinar muito com suas escolhas, se estivermos dispostos a aprender com eles um modo mais antenado, esperto, polissensorial e animado de viver.
Atentos aos jovens, descobriremos que eles nos ensinam a não criar um antagonismo entre leituras e tecnologias midiáticas. Mostram-nos a todo momento que "também se aprende a ler e a ser espectador sendo telespectador e internauta", e mais ainda, que "ser internauta aumenta, para milhões de pessoas, a possibilidade de serem leitores e espectadores" (CANCLINI, 2008, p. 24 e 54).

O gosto pelos textos escritos, pela boa literatura, ensinam nossos jovens estudantes, não precisa se sobrepor ou se antepor ao gosto pelos artefatos da indústria de entretenimento, mas, no mundo da mistura das linguagens e da desterritorialização das identidades, no mundo das imagens e da banalização da cultura, nesse mundo que eles nos ensinam a habitar, o livro e a palavra convivem com os demais produtos culturais e associam-se à rede de informação e lazer disponível em tantos outros suportes e modos de expressão. $\mathrm{O}$ menino que acompanha a aula ligado na tela do celular não está necessariamente conversando com os amigos, mas pode estar acompanhando o último exercício que o velho professor enviou por e-mail. Sites de bibliotecas, acervos públicos de obras literárias, livros que podem ser baixados e arquivados nos computadores pessoais, páginas de museus e galerias de arte com acesso a milhares de obras de arte antes só disponíveis aos endinheirados que viajavam e frequentavam tais ambientes, tudo isso prova que o conhecimento 
se abre para um público mais amplo e diversificado e que é preciso aprender a ler em outros suportes. Será igualmente importante conhecer a poesia de Camões, descobrir o site de poesia concreta de Augusto de Campos, surpreender-se com os romances de Machado de Assis, acessar obras literárias integrais de domínio público, ler poesia romântica nos livros da biblioteca, percorrer blogs de contistas contemporâneos e aprender a fazer pesquisa consultando sites de busca. Googlar não precisa ser apenas um neologismo incômodo, podendo conter na ideia que dissemina um movimento de conquista de novos meios e recursos.

A escola tem dupla missão: absorver as novas tecnologias e aproveitar seu potencial de produção de sentido e, ao mesmo tempo, insistir sempre na literatura e na arte, porque livros, quadros, esculturas, ao exigirem o silêncio e a contemplação da apreensão estética, representam a resistência e o assombro capazes de ressignificar a vida e dar-lhe nova direção.

A imersão nas páginas de um romance, no ritmo de um poema ou nas cores de uma pintura é capaz de nos alhear do mundo por instantes e nos fazer retornar de outro modo a esse mesmo mundo. É experiência semelhante à contemplação do mistério das folhinhas de nogueira que Calvino viu cair da árvore. Volteando no vento, as folhinhas - duas, três, quatro, quantas mais, diz Calvino (1999, p. 203) - obrigam nossos olhos a acompanhá-las, perceber seu volteio, vê-las aproximarem-se e afastarem-se "como borboletas que se perseguem", para enfim pousarem no solo. Esse percurso do olhar que acompanha o movimento das folhas da árvore se assemelha àquele do movimento dos olhos nas folhas dos livros: tantos mundos, tantos mistérios se desprendem daquelas páginas, voam em nossas imaginações, inquietam e entristecem nossos corações, animam nosso corpo, movimentam-se em variadas direções, circunvolteiam em nossa mente, para afinal pousar de novo nas mesmas páginas que outros lerão, não sem antes ter transtornado nosso olhar e recuperado nosso poder de dúvida, insatisfação, indignação, encantamento.

A internet e a pluralidade de linguagens que representam novas exigências de leitura no mundo contemporâneo, entretanto, não podem estar afastadas da escola e parece que ainda hoje se constituem em mistérios para práticas pedagógicas que antagonizam o que chamam de alta e baixa cultura. Fechando-se à novidade, a escola vai ficando cada vez mais distante do universo juvenil e mais afastada das reais possibilidades de tocar afetos e interesses do público estudantil, sobretudo dos ensinos fundamental e médio. Será preciso incorporar à aula de português a $\mathrm{HQ}$, a charge, o jornal, o blog e o site, analisar poemas e pinturas, grafites e narrativas densas, gravuras e programas de TV.

Para isso, é necessário um saber, um domínio metodológico e teórico que ofereça os instrumentos pedagógicos para 
uma leitura crítica e proveitosa. Não há bom ensino sem boa teoria, não há possibilidade de fazer avançar o conhecimento oferecido pela escola se não se faz avançar também a teoria que fornece a base de atuação prática dos docentes. Em suma, não há ensino de boa qualidade sem pesquisa consistente.

A semiótica francesa oferece as bases teóricas que fundamentam a metodologia que se vai propor neste artigo, elege o texto como objeto e o percurso de produção de sentido como o modelo de previsibilidade a descrever. Escolher uma teoria que estuda os textos como objetos de sentido significa fazer uma opção pedagógica, a de privilegiar o texto como unidade de trabalho, em torno da qual se desenvolvem as atividades de compreensão de vocabulário, interpretação, expressão oral e escrita e análise das estruturas gramaticais.

A aula de português deve girar em torno da análise de um texto, que pode se apresentar nas mais diferentes materialidades e nas mais exuberantes configurações multimodais. Diante da multiplicidade de ofertas do universo da cibercultura e dos inúmeros artefatos de linguagem próprios das sociedades contemporâneas, a escola precisa desenvolver métodos que deem conta do caráter multissensorial e das potencialidades significantes dos textos em circulação.

Paul Claudel dizia que, para observar uma pintura, eram necessários "todos os recursos da paciência e da sintaxe" (CLAUDEL, 2003, p. 133). Essa paciência, que Floch tão bem justificou pela necessidade de alhear-se do acessório e da dispersão proposta pela "torrente de imagens" dos apelos visuais do mundo (2002, p. 4), faz-se da duratividade da observação, necessariamente contraposta à subitaneidade de um impacto. Desacelera-se o impacto, para que ele ganhe sentido, para que vá além da emoção ou do susto. A sintaxe entra necessariamente nesse movimento desacelerado de desconstrução, em que letras, linhas, cores e movimentos são segmentados para alcançar a composição, a organização que confere à ideia uma forma. A análise é um movimento de desconstrução, por meio do qual se perde o efeito de unidade da criação para se chegar a uma unidade de interpretação.

Definindo-se como teoria geral do texto e da significação, a semiótica ocupa-se da produção de sentido de um texto por meio de uma metodologia que considera a articulação entre um plano do conteúdo e um plano da expressão e categorias gerais de análise capazes de, por um lado, contemplar a totalidade dos textos, manifestados em qualquer materialidade e, por outro lado, definir as estratégias enunciativas particulares dos textos concretos. É esse o modelo teórico que adotamos a seguir.

\section{Semióticas sincréticas}

O objeto da semiótica, já dissemos, é o texto, manifestado por todo e qualquer tipo de expressão e compreendido a um 
só tempo como objeto de significação e de comunicação. A abrangência dessa escolha epistemológica faz com que a teoria se volte para os aspectos responsáveis pela estruturação interna do texto, ao mesmo tempo em que busca compreender as relações entre enunciador e enunciatário. Representados concretamente, grosso modo, pelas figuras de autor e leitor, esses assumem nos textos posições discursivas que simulam a interação entre os sujeitos no mundo e constroem discursivamente a busca pela adesão, as estratégias de convencimento, a partilha ou a disputa de vozes. $\mathrm{O}$ texto, portanto, produto das escolhas de um enunciador e do fazer interpretativo de um enunciatário, compreende uma complexa rede discursiva caracterizada pela escolha de gêneros e tipos textuais, a instauração de estratégias argumentativas e a adoção de determinados modos de interação. Além disso, todo texto faz uso de ferramentas discursivas, para demonstrar formalidade ou informalidade, construir efeitos de aproximação ou de distanciamento, simular objetividade ou subjetividade. Somam-se a tudo isso, ainda, os procedimentos da expressão que, dando forma ao conteúdo, também significam. A adaptação de um romance para uma minissérie sofre as coerções da nova mídia, da linguagem audiovisual, e será necessariamente outro texto, outro modo de dizer. Essa complexidade pressupõe uma coerência interna capaz de conferir aos textos unidade e homogeneidade. $\mathrm{O}$ surgimento de novas ferramentas tec- nológicas e a sofisticação dos meios de expressão põem em foco a questão da unidade de sentido dos textos e desafiam as teorias a construir um instrumental analítico que permita operar com a relação entre variedade significante e totalidade de sentido.

A noção bakhtiniana de gêneros como "tipos relativamente estáveis de enunciados" (BAKHTIN, 2003, p. 262) se mostra duplamente interessante para a semiótica, pois aponta para a possibilidade do estabelecimento de tipologias que tornam os textos objetos passíveis de análise, de descrição e de categorização, ao mesmo tempo em que pressupõe a abertura para a novidade e a criação. Para a semiótica, o uso e a repetição de estratégias enunciativas, de gêneros, tipos e estilos é tomado como uma práxis. Assim, a práxis enunciativa é responsável por atualizar no discurso "as formas esquematizadas pelo uso ou, ainda, estereótipos e estruturas cristalizadas" (FONTANILLE, 2007, p. 271). De outro modo, é essa mesma práxis que prevê como possibilidade o surgimento de novas significações, a partir dos desvios, das subversões e das expansões dessas formas ou do emprego de novas formas e estruturas, "inovando de forma explosiva, assumindo-as como irredutivelmente singulares ou propondo-as para um uso mais amplamente difundido" (FONTANILLE, 2007, 272). Com isso, a semiótica lança sobre a enunciação um ponto de vista dinâmico e passa a conceber o texto como uma unidade em 
movimento, resultante do equilíbrio entre retomadas e avanços, continuidades e descontinuidades.

Muitas palavras têm sido empregadas para tentar dar conta do advento de novos gêneros e tipos textuais. Fala-se muito em "hibridismo", "multimodalidade", "intergenericidade". A escrita e a leitura hipertextual são vistas como o desdobramento previsível, como o "futuro" da escrita e da leitura textual (cf. LÉVY, 1993, p. 19). A convergência entre diferentes mídias faz com que as narrativas deem lugar à criação de "universos", "ambientes atraentes que não podem ser completamente explorados ou esgotados em uma única obra, ou mesmo em uma única mídia" (JENKINS, 2009, p. 161). Diante disso, que noção de texto deve permear o trabalho de leitura e interpretação? Que porta de entrada, para textos cada vez mais sofisticados, os professores podem e devem apresentar aos seus alunos nas aulas de língua portuguesa?

Entre as teorias que vêm oferecendo instrumental metodológico consistente e de larga utilização por estudiosos do discurso no Brasil, para a leitura de textos caracterizados pelas relações entre diferentes linguagens, estão a semiótica social de Kress e van Leeuwen e a semiótica discursiva, de origem greimasiana, também chamada semiótica francesa.

Os analistas da semiótica social têm estudado particularmente textos em que podem utilizar a gramática do design visual proposta por Kress e Van Leeuwen
(1996). São, então, identificadas estratégias de persuasão por meio de elementos visuais (cores, ângulos, poses) e linguísti$\cos$ (modos e processos verbais, colocação de pronomes, adjetivos) e consideram-se as correspondências entre sintagmas visuais e aqueles que existem na sintaxe da linguagem verbal. Analisam-se as estruturas narrativa e conceitual e busca-se um significado cultural comum a autor e leitor ou espectador. Conferindo relevância às práticas sociais, de forma que a comunicação é considerada como processo em que os objetos semióticos são produzidos e interpretados, havendo, portanto, uma articulação consequente entre, por exemplo, o ato de planejar um jardim e o modo como os usuários o aproveitam: como parque de diversões, descanso, local de encontros etc. A fruição do objeto liga-se à intenção com que foi produzido, firmando-se uma conexão entre sujeitos. A postulação da semiótica social tem sido integrada à análise crítica do discurso e a aplicada às concepções de texto utilizadas no ensino de línguas.

Na concepção da semiótica discursiva, a intenção de um sujeito é substituída pela intencionalidade do texto, considerada como direção do sentido, dada pela articulação dos três níveis do percurso: 0 fundamental, em que uma oposição abstrata e abrangente estabelece o mínimo de sentido a partir do qual o texto se produz; o narrativo, em que entram em cena sujeitos em busca de valores investidos em objetos; o discursivo, em que temas e figuras recobrem os conteúdos abstratos 
e operações enunciativas projetam no texto as categorias de pessoa, tempo e espaço e as estratégias argumentativas. Esse percurso de produção do conteúdo ganha forma por meio de um plano da expressão, a materialidade significante de cada linguagem. Assim, um cartaz de campanha de vacinação opera com a oposição fundamental entre vida e morte; contém a narrativa da transformação do estado do sujeito, de potencialmente doente a saudável, por meio da conjunção com a vacina, e formaliza uma cobertura figurativa, por exemplo, quando o desenho de uma gotinha dá forma à vacina antipólio. No plano da expressão, esse conteúdo aparece num cartaz, por meio de arranjos do texto verbal e dos desenhos no espaço do suporte, jogos de cores etc, constituindo uma unidade verbo-visual.

Para dar conta de textos formados pela multiplicidade de linguagens, como um cartaz, uma página de jornal, um blog ou uma história em quadrinhos, a semiótica operacionaliza o conceito de sincretismo. Serão definidos como sincréticos os textos cujo plano de expressão é caracterizado pela mobilização de múltiplas linguagens apreendidas na mesma enunciação. Assim, ao ter diante de si uma primeira página de jornal, o leitor percebe uma unidade de expressão entre texto verbal (diferentes tipos, cores e tamanhos de fontes) e texto visual (diferentes tamanhos, cores e composição da fotografia). Essa unidade de expressão se homologa aos conteúdos expressos pelo verbal no texto das manchetes, nos subtítulos, e visualmente nas figuras retratadas pelas fotografias e nos gráficos, desenhos e charges.

O conceito de sincretismo em semiótica possui duas acepções. A primeira é herdeira direta da definição de Hjelmslev e diz respeito ao procedimento (ou ao resultado) que estabelece, por meio de uma superposição, uma relação entre dois (ou mais) termos ou categorias diferentes reunidos por meio de uma grandeza semiótica ou linguística (cf. GREIMAS e COURTÉS, 2008, p. 467). Observemos um exemplo:

[...] em português, as grandezas /e/ e /i/ são invariantes do esquema linguístico, uma vez que distinguem "lê" de "li" (/le/vs /li), "vê" de "vi" (/ve/ vs /vi/), etc. Mas, em certas condições de uso como, por exemplo, em posição átona final, essas invariantes se superpõem no sincretismo /I/ (/dentI/ "dente", "solte") (CARMO JR., 2009, p. 172).

Esse sincretismo é possível graças aos traços comuns entre /e/ e /i/ (anterior e não arredondada), que torna $\mathrm{o} / \mathrm{I} / \mathrm{um}$ som intermediário entre /i/ e /e/. De acordo com a definição de Hjelmslev, por meio do sincretismo uma diferença transforma-se numa identidade (cf. CARMO JR., 2009, p. 171). Há neutralização da oposição. No nível da sintaxe narrativa, numa frase como "Joana penteou-se", o sujeito frasal é um sujeito de estado, que está em conjunção com o objeto "cabelo despenteado" e com o objeto "pente" e é, ao mesmo tempo, o sujeito do fazer que pratica a ação de "pentear-se", transformando o estado do cabelo de "despente- 
ado" em "penteado". O papel actancial que une os dois sujeitos (de estado e de fazer) resulta de um sincretismo.

A segunda acepção de sincretismo tem um caráter mais amplo e trata das chamadas semióticas sincréticas, que se caracterizam pela mobilização de múltiplas linguagens de manifestação, como um programa televisivo, um filme, uma história em quadrinhos, entre outras. $\mathrm{O}$ estudo de textos sincréticos tem como tarefa descrever e explicar as estratégias de construção do efeito de unidade, observando como as diferentes substâncias do plano da expressão (de agora em diante $\mathrm{PE}$ ) se articulam para produzir uma forma coerente e apreensível como um todo no plano do conteúdo (de agora em diante PC). A análise do objeto sincrético deve ainda considerar as especificidades de manifestação próprias de cada texto: um jornal impresso (verbo-visual) e um telejornal (audiovisual) exemplificam essas particularidades. A relação entre as diferentes linguagens ocorre num continuum de solidarização que vai da convergência, entendida como grau máximo de solidariedade, à divergência. Regina Gomes, ao analisar o sincretismo em textos de mídia impressa, considera que há uma "relativa independência" entre a fotografia e o relato verbal da notícia e que verbal e visual se relacionam por justaposição. Gomes (2009) parte da proposta de que existem três modos de estruturação do sincretismo em função da materialidade visual e/ ou sonora de cada texto. Há textos que se estruturam espacialmente, como é o caso da mídia impressa, em que os elementos visuais (fontes, fotos, desenhos etc., submetidos a uma diagramação que opera com categorias como cor e forma) são arranjados no espaço. Outros textos se organizam temporalmente, como as emissões radiofônicas, que congregam múltiplas substâncias sonoras. Outros ainda sobrepõem elementos visuais e sonoros, como o teatro, a TV e o cinema. A autora diferencia as relações de adjunção que decorrem da justaposição entre as linguagens, das relações de sobreposição ocorridas em simultaneidade (cf. GOMES, 2009, 222-223, grifos nossos). Entretanto, adverte que essas relações podem ser subvertidas em situações pontuais:

Na televisão, por exemplo, é possível a ocorrência de texto sobre fundo preto ou branco, estático, justaposto à imagem, sem a presença de uma voz em off que $o$ anuncie oralmente. Na imprensa, é possível a sobreposição entre as linguagens verbal e visual. No entanto, esses modos de presença das linguagens, nos diversos veículos de comunicação, podem causar estranhamento, por não habituais, produzindo efeitos de sentido particulares (GOMES, 2009, p. 223).

A observação de Gomes, ao considerar usos mais ou menos habituais de cada veículo de expressão se relaciona ao conceito de práxis enunciativa, em que os usos podem se fixar ou se renovar. Assim, a análise de textos sincréticos precisa considerar a relação estabelecida entre o PE e o PC das múltiplas linguagens que os compõem e também os modos de funcionamento específicos 
de cada linguagem, tais como linearidade vs. concomitância que diferenciam, por exemplo, a linguagem verbal das linguagens visuais. Com efeito, as diferentes linguagens em um texto sincrético estão submetidas à enunciação que as condensa e confere a elas o sentido de unidade. A enunciação põe o discurso em andamento e assim legitima pelo uso determinadas práticas significantes. A semiótica discursiva buscou enfrentar a questão do sincretismo, a fim de compreender como essa "heterogeneidade multimodal" (FONTANILLE, 2008, p. 33) se converte em unidade. A partir de variadas análises de textos sincréticos, do aprofundamento do exame da visualidade e dos avanços da teoria, percebe-se certo consenso acerca do papel da estratégia enunciativa como dispositivo capaz de conferir unidade à pluralidade de elementos (TEIXEIRA, 2009, p. 63).

Pensando em categorias gerais de análise de textos sincréticos, elegeremos o par sobreposição e justaposição de linguagens que nos parece dar conta, ao menos de modo geral, da relação estabelecida entre os sincretismo audiovisual e verbo-visual. Esses modos gerais de funcionamento dos textos sincréticos se aliam à estratégia enunciativa que liga as linguagens aos diferentes modos de apreensão (linearidade, concomitância). Além disso, cabe à estratégia enunciativa relacionar o PE e o PC das múltiplas linguagens, de modo a ampliar ou restringir conteúdos, sobrepor ou justapor elementos de modo mais previsível e habitual ou de modo mais inusitado e insólito. Uma primeira página de jornal (verbo-visual), por exemplo, constrói um sincretismo por justaposição, que rege dois modos distintos de apreensão: a concomitância da linguagem visual e a linearidade da linguagem verbal. Entretanto, a apresentação da primeira página põe em relevo a visualidade, de modo que o que se torna proeminente é a organização topológica dos elementos: a distribuição das fotografias, a organização das colunas, os tamanhos e as distribuições de diferentes fontes. A categoria do espaço, digamos, é a porta de entrada para esse texto. Já um texto audiovisual opera por meio da sobreposição de linguagens numa linearidade, tornando central a temporalidade. Yvana Fechine (2009, p. 335), ao analisar o sincretismo em textos audiovisuais, adverte que, para analisar as unidades em jogo no audiovisual, é preciso "analisar as articulações que fundam a cadeia audiovisual na sua sucessividade (um plano após o outro) e simultaneidade (superposição de expressões nos planos)". Entretanto, considera que o conteúdo audiovisual no cinema, por exemplo, surge "da superposição dos conteúdos visual e musical" (Idem, p. 338).

Esses modos de funcionamento organizam as relações entre as linguagens num determinado suporte por meio de um ponto de vista enunciativo e são responsáveis por criar o sincretismo propriamente dito. Em outras palavras, 
as diferentes linguagens manifestam-se de modo heterogêneo e cabe ao sincretismo dado pela estratégia enunciativa resolver essa heterogeneidade. No caso do texto jornalístico:

$\mathrm{O}$ fato de as imagens fotográficas estarem subordinadas pela manchete principal e envolvidas pelo verbal escrito, que as circunda, é uma primeira pista e uma estratégia do sujeito da enunciação para que o leitor tome todo o conjunto como um só conjunto significante (GOMES, 2009, p. 243).

O estudo das semióticas sincréticas exige, ainda, um exame mais profundo da visualidade. Os sistemas visuais demandaram da semiótica um esforço de discriminação das categorias da expressão visual, que acabaram por delinear o projeto de uma "semiótica plástica". Jean-Marie Floch defende que o tratamento cromático e gráfico de uma imagem pode operar uma rearticulação dos signos figurativos (Floch, 2009, p. 166). O estabelecimento de categorias plásticas permite um refinamento do exame de combinações e contrastes de cores (categoria cromática), das relações entre formas (categoria eidética), da organização do espaço (categoria topológica) e dos efeitos construídos pela materialidade significante (categoria matérica). Ao examinar tais categorias busca-se mapear os efeitos de sentido construídos na articulação entre expressão e conteúdo. Assim, categorias topológicas como alto vs. baixo e eidéticas como retilíneo vs. curvilíneo podem construir no PE efeitos de contenção vs expansão que correspondam a estaticidade $v s$ dinamicidade no PC (TEIXEIRA, 2009, p. 67). Uma análise clássica e modelar de Floch sobre a linguagem publicitária da campanha de lançamento do cigarro News mostra que a oposição da expressão /descontinuidade/vs. /continuidade/ se articula à oposição de conteúdo /identidade/ vs. / alteridade/ (FLOCH, 2009, p. 161).

A leitura de textos sincréticos, portanto, precisa considerar o funcionamento geral estabilizado pela práxis enunciativa e o minucioso exame das categorias da expressão de cada linguagem. Esse percurso de análise inclui, no nível mais superficial e concreto, o exame dos temas e das figuras disseminados no discurso. Os temas, mais abstratos, como "riqueza", por exemplo, são recobertos por figuras, mais concretas, como: "dinheiro", "joias", "propriedades", "mesa abastada", "luxo", "herança". O famoso personagem de Walt Disney, tio Patinhas, ao aparecer mergulhando ou admirando suas montanhas de moedas, figurativiza a riqueza do avaro, daquele que acumula. Não só as figuras moedas e Patinhas, mas os recursos de expressão do brilho amarelado das moedas e do traço ascendente da boca do personagem, em estado de alegria, configuram o caráter ideológico dos mecanismos de figurativização e acentuam a visão capitalista da riqueza como acúmulo individual de bens. Por meio de cadeias construídas pela reiteração de elementos (verbais, visuais, sonoros) denominadas cadeias isotópicas, os textos constroem percursos de leitura e garantem sua coerência. Os programas 
de auditório de televisão destinados às chamadas camadas populares, controlados por um enunciador que argumenta pelo exagero e a desmedida, fundam-se numa estética do excesso, manifestada, no plano do conteúdo, num sortimento variado e numeroso de figuras e numa simulação de participação interativa do público, e, no plano da expressão, em elementos como multicromatismo, tomadas de câmera, iluminação intermitente, sonoridade acelerada e preenchimento pleno do espaço. Esse tipo de texto sincretiza as múltiplas linguagens por meio da aceleração da expressão e da saturação do conteúdo e, com isso, tematiza-se a alegria, a vivacidade, a empolgação.

\section{Metodologia de análise}

Passemos ao exame de alguns textos sincréticos, com a finalidade de exemplificar as possibilidades de abordagem concreta de textos desse tipo na escola.

\section{Ler e interpretar HQs}

As histórias em quadrinhos são textos sincréticos do tipo verbo-visual, em que uma sequência de quadros com desenho e, em geral, texto verbal apresentado em balões, desenvolve uma narrativa. Podem concretizar-se em diferentes gêneros, como a tira de humor, a história de aventuras, os quadrinhos de terror etc. A leitura desse tipo de texto pressupõe do leitor uma competência para apreender e relacionar a sequência construída pelos conteúdos verbais contidos nos balões de fala ou comentários do narrador com os conteúdos apresentados visualmente. $\mathrm{O}$ sincretismo se realiza por meio da instauração de cadeias temáticas e figurativas nas diferentes linguagens. $\mathrm{O}$ conceito de isotopia diz respeito à recorrência, à retomada de temas e figuras, de modo que sejam construídos percursos que indicam um caminho de leitura. No caso de textos sincréticos verbo-visuais, $o$ verbal e o visual podem confirmar a mesma isotopia, restringindo a leitura, ou podem desencadear isotopias distintas. A relação entre as linguagens pode ser marcada por harmonia ou conflito, pode instaurar a reiteração ou o contraponto entre os conteúdos que veiculam. No caso das HQs do tio Patinhas, quando o personagem exclama "Ah, como isto é bom! O contato do ouro na pele é revigorante!" e mergulha na sua piscina de moedas, com expressão sorridente e movimentos cheios de vivacidade, o visual reitera o verbal e vice-versa. Numa HQ de humor, um personagem que cai de joelhos em declaração apaixonada à amada, cria imagem que pode ser contestada por olhares, gestos e balões de pensamento da mulher a quem se declara.

Nas tiras, em que a sequência narrativa se mostra horizontalmente, em geral em três quadros que condensam todas as características das HQs, podemos observar com mais detalhes essas formas de relações entre linguagens: 
Figura 1

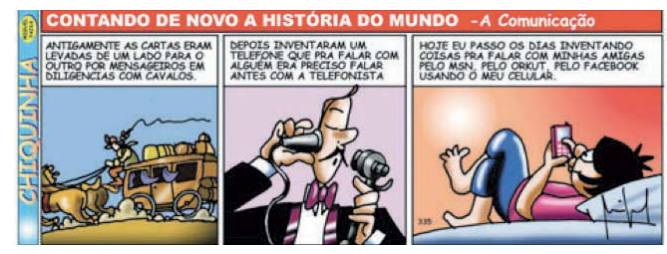

Fonte: Miguel Paiva, O Globo, Globinho, 15 jan 2011, p. 8.

Na tira de Chiquinha, a tarja superior, em cor vermelha, dá destaque ao título, que anuncia uma nova forma de contar a história da humanidade. O subtítulo convoca a temática da comunicação, pormenorizada na tira por meio da isotopia figurativa construída no texto verbal - "cartas", "telefone/ telefonista", "MSN", "Orkut", "facebook" e "celular". Essa cadeia figurativa instaura verbalmente uma sequência que guia o percurso de leitura. Levar o aluno a mapear essas informações e a perceber o percurso figurativo como uma representação linear da evolução dos meios de comunicação pode ser um primeiro passo de leitura desse texto.

A observação das figuras visuais, por meio da descrição dos elementos de cada quadro, revela que há uma reiteração dessa sequência dada pelos elementos visuais: carroça (que conduz as cartas), telefone antigo e celular moderno. No segundo quadro, por exemplo, o tema da antiguidade é dado também pelas roupas, pela gravata borboleta, pelo corte de cabelo e o tipo de bigode do personagem retratado. Já no último quadro, o tema $\mathrm{da}$ atualidade se relaciona às facilidades e ao conforto, construindo a ideia de que as ferramentas de comunicação mais recentes facilitam a vida. A passagem da dificuldade à facilidade, do desconforto ao conforto, constrói narrativamente a ideia da transformação do mundo por meio do contraste entre a dureza e a truculência da carroça e a suavidade e maciez da cama e do travesseiro de Chiquinha. No $\mathrm{PE}$ visual, o exame dos formantes cromáticos confirma essa narratividade, pois a passagem do tempo se dá pela diferença entre cores apagadas e opacas nos dois primeiros quadros - fundo azul, tons terrosos e marrom na carroça e nos cavalos (quadro 1); fundo lilás, vinho, preto e branco da roupa do homem (quadro 2) - e cores mais vivas e brilhantes no último - fundo laranja, rosa e azul vibrante da roupa de Chiquinha, marcadas por pontos de luz. Assim, constrói-se a ideia de que os acontecimentos passados são esmaecidos pelo tempo, ao passo que o brilho das cores marca o frescor do presente. Além disso, a ordem dos quadrinhos na página (recurso visual) compõe a estratégia enunciativa que ordena temporalmente a apresentação dos fatos e encontra eco na temporalização verbal dada pelos advérbios "antigamente", "depois" e "hoje" usados em sequência em cada quadro e pelo emprego de verbos no pretérito nos dois primeiros quadrinhos e no presente no último.

Observando, ainda, o visual por meio das categorias eidéticas vê-se que a relação entre as formas da figura humana é contrastante. A passagem da verticalidade, nos dois primeiros quadrinhos, à horizontalidade, no último quadro, põe em relevo discursivamente um percurso que vai da tensão ao relaxamento, da conten- 
ção à distensão. $\mathrm{O}$ texto verbal contrapõe distanciamento e aproximação, por meio das categorias da enunciação. Assim, o tempo do "então", de "antigamente", em que a comunicação exigia intermediários (mensageiros/ telefonistas) se opõe ao "hoje", momento próximo da enunciação em que um eu que enuncia é projetado discursivamente. A oposição entre o lá/então e o aqui/agora constrói sintaticamente a passagem do tempo e o desenrolar da história do mundo. $\mathrm{O}$ conteúdo da facilidade e da agilidade da comunicação é construído por meio da articulação entre as linguagens, que, no caso em análise, se deu por reafirmação e reiteração entre verbal e visual.

Tiras são textos ricos para análise, porque possibilitam, com economia de recursos, a compreensão de um fio narrativo. Além disso, operam com riqueza de procedimentos de expressão. Não podem figurar apenas como ilustração de algum conteúdo, devendo ser exploradas em toda a sua potencialidade de geração de sentidos. Analisar uma tira pode render não só a compreensão do emprego de categorias da expressão visual, mas também a produção escrita de textos narrativos, a formatação de diálogos, e ainda a apresentação dramatizada de uma história.

\section{Navegar em sites da internet}

Ainda que se use a internet com frequência e com naturalidade, muitos estudantes ainda não são capazes de analisar sua organização e funcionamento, o que pode ser fundamental para uma "navegação" segura e produtiva. Um site constitui-se no formato de um hipertexto, isto é, um conjunto de nós e de links, que permitem a navegação por um conjunto de páginas relacionadas entre si, armazenadas de maneira virtual.

Enquanto o texto é uma estrutura linear, hierarquizada, o hipertexto é uma estrutura de rede, na qual os elementos textuais são nós, ligados por relações não lineares e pouco hierarquizadas, manifestadas pelas diversas linguagens que se articulam numa totalidade de sentido sincrética.

Veja-se um exemplo:

Figura 2

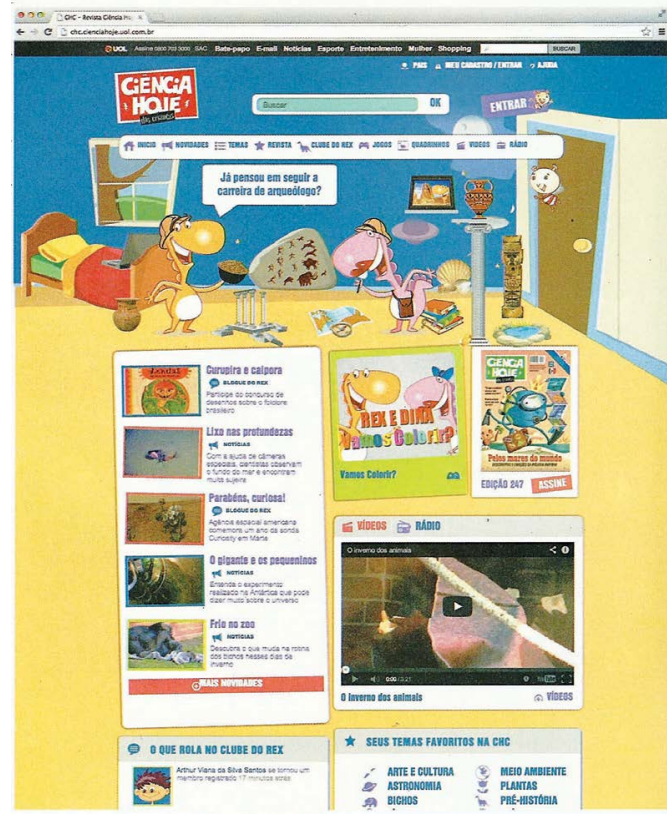

Fonte: Ciência Hoje das Crianças. Disponível em: http:// chc.cienciahoje.uol.com.br/ Acessado em: 27 ago. 2013. 
Para depreender como se dá o sentido nos textos, o analista fragmenta suas partes, observando-as atentamente e descrevendo-as detalhadamente. A partir daí, examinam-se os procedimentos adotados para construir o sentido do texto.

Ciência hoje das crianças $(\mathrm{CHC})$ é o site da revista de mesmo título do Instituto Ciência Hoje. De forma alegre, descontraída, o site busca despertar curiosidade científica nas crianças. Será analisada aqui a capa do site, aquela que se abre quando o endereço do link é digitado. A capa é o primeiro contato do internauta com os sites de internet e esse contato se dá por meio da $1^{a}$ rolagem da página, a parte superior.

A configuração topológica do site da $C H C$ se dá na divisão nítida entre a $1^{\underline{a}}$ rolagem e o restante da página, horizontalmente. A fronteira entre as partes é constituída pela linha não demarcada que está abaixo dos dinossauros. A $1^{\text {a }}$ rolagem apresenta-se de forma bem diferente da parte superior, entretanto há uma harmonia no ajuste entre as partes na formação da unidade do site.

O arranjo topológico da $1^{\mathrm{a}}$ rolagem é constituído principalmente de forma horizontal, em faixas. A composição cromática se caracteriza pela cor azul escura ao fundo, em contraste com o título do site, em vermelho e branco, chamando a atenção do leitor, do lado esquerdo. $\mathrm{Na}$ parte superior central, há um box verde de busca e ao seu lado direito um link para a autenticação no site com a indicação "entrar" e um desenho de uma abelha. Centralizado, abaixo, está o menu do portal, com os principais links de acesso, composto pelo fundo branco, fonte azul e ícones roxos. Ao passar o mouse sobre os links, suas cores ressaltam, em vermelho, chamando a atenção do usuário. As cores em harmonia colaboram na organização do percurso do internauta pelo site. A observação e a descrição visual do site funcionam como primeira etapa da análise.

Dois dinossauros estão dispostos na parte central da $1^{\mathrm{a}}$ rolagem, configurada de forma ampla, tomando todo o campo visual da tela. Eles se movimentam e dialogam entre si e com os leitores, em um espaço que reproduz o ambiente de um quarto, concretizado pela cama posta à esquerda, próxima de uma janela, e a porta fechada à direita. A organização topológica dos elementos nessa parte da $1^{\text {a }}$ rolagem captura o leitor para o tema em destaque. Os objetos que compõem o espaço desse quarto e as vestimentas dos dinossauros estão relacionados à principal matéria do veículo naquele período: arqueologia. Mapas, bússola, desenhos rupestres, livros são figuras que compõem a área central da $1^{\mathrm{a}}$ rolagem com os dinossauros, concretizam o tema da matéria principal e auxiliam na ambientação dos internautas com o assunto. Figuras principais, os dinossauros movimentam-se e olham para fora da tela. Um deles, o da esquerda, faz um convite ao internauta, em discurso direto "Já pensou em seguir a carreira de 
arqueólogo?". A pergunta revela-se como uma interpelação que cria a interação do personagem com o internauta. Os elementos citados anteriormente, dispersos pelo quarto, são ícones configurados em hiperlinks que levam o leitor a uma página sobre o tema. O discurso direto aparece num balão de fala, recurso comum em $\mathrm{HQ}$, que estabelece familiaridade com o usuário. O uso desse recurso, aliado à expressividade dos personagens, reforça a estratégia de persuasão estabelecida pelo enunciador.

A organização da parte inferior da página, de fundo bege, simula o chão do quarto, alargando a dimensão do cômodo, e está divida em dois blocos. À esquerda há uma coluna com cinco chamadas para as diversas seções que compõem o site. Essa coluna vertical, contornada por uma fina e discreta linha, apresenta fundo branco com as chamadas em links, dispostas horizontalmente. À direita, diferentemente, há três boxes separados. Nos dois menores, há um link de atividade para colorir e outro com uma chamada para a revista impressa; eles estão dispostos sobre um boxe maior, com links para vídeos e rádio. Tais chamadas em formato de links são constituídas de elementos verbais e não verbais.

É nítido o contraste entre a $1^{\underline{a}}$ rolagem e a parte inferior do site. A $1^{a}$ rolagem é mais ampla, os elementos dispostos de forma dispersa pelo quarto remetem ao ambiente do quarto do leitor, criando um vínculo por meio da familiaridade com um espaço conhecido da criança. Os elementos que figurativizam o tema em destaque na edição preenchem o espaço do quarto, substituindo os elementos comuns de um quarto infantil: uma bola, uma boneca, uma mochila ou um par de patins. $\mathrm{O}$ arranjo desses elementos que dão segurança ao leitor também o persuade a navegar pelo site com mais interesse e curiosidade.

A movimentação pelo site apresenta-se de forma dinâmica e rápida, e a atualização é constante, com a entrada de novos temas e reportagens. Os dinossauros mudam de ambiente e de roupa de acordo com os novos conteúdos expostos. Entretanto, a composição estrutural do site permanece a mesma, a disposição do título, do boxe de busca, do menu, por exemplo, mantém-se sempre no mesmo lugar. Esse arranjo sincrético preserva a identidade visual do site, imprimindo-lhe um perfil particular, ao mesmo tempo em que cria certo conforto para o internauta e instaura uma prática de acesso ao site.

As categorias topológicas e cromáticas do plano da expressão, articuladas entre si e com o plano do conteúdo, geram o efeito de sentido de harmonia e totalidade e são apreendidas na mesma enunciação. Essa articulação também gera o efeito de sentido de curiosidade e relaciona o aprendizado à diversão, pois a navegação se dá de forma lúdica, de acordo com temas direcionados ao público infantil. Mostrar aos alunos as funções dos links e as relações estabe- 
lecidas entre as linguagens é fazê-los compreender o gênero e interpretá-lo. Da mesma forma, analisar o sentido de cada figura ou dos recursos de expressão que criam o efeito de interatividade pode levar o aluno a ter consciência de que nada num texto é gratuito, tudo se harmoniza para criar um programa de manipulação, por meio do qual o enunciador busca a adesão do enunciatário.

\section{Analisar a capa do jornal}

Analisar e interpretar o gênero capa de jornal na sala de aula é uma atividade que estimula a capacidade crítica dos alunos, se puderem perceber os efeitos das escolhas feitas pelo jornal. Funcionando como uma espécie de "vitrine" da edição do dia, a capa atrai a atenção dos leitores e tem por função convencê-los a comprar o jornal e ler suas páginas. A temática da capa refere-se às principais notícias da edição, variando o estilo e a composição de acordo com o público leitor a que o órgão se destina.

Para a leitura do jornal, não se pode dissociar texto verbal e imagem, pois ambos estão articulados em um todo de sentido, logo, a apreensão do sentido se dá por essa correlação entre a pluralidade de linguagens. Regina Gomes afirma que

A estratégia enunciativa, ao empregar procedimentos de sincretização de linguagens, ajuda a construir a identidade semiótica de um jornal, selecionando o enunciatário ao qual se dirige. Empresta-lhe, também, visibilidade, acrescentando-lhe um traço diferencial no meio do ruído intermitente provocado pela saturação de informações que circulam na sociedade contemporânea (GOMES, 2008, p. 85).

Como já foi assinalado anteriormente, o todo de sentido produzido pelo texto sincrético é produto de um único enunciador que se mostra habilidoso em articular as múltiplas linguagens em relação: "não há, por isso, uma enunciação verbal e outra visual, outra melódica, e assim por diante, mas uma só enunciação que mobiliza, no plano da expressão, uma pluralidade de substâncias estruturadas sob uma só forma" (GOMES, 2008, p. 85).

Na capa são selecionadas, pelo enunciador, chamadas de notícias, suscetíveis de funcionar como apelo a uma rápida leitura, a uma "olhadela":

Esse modo de fazer ver - e fazer saber ligeiro, descontínuo, abrangente, faz com que uma primeira apreensão do sentido se dê através de apenas alguns elementos textuais colocados em destaque, em detrimento de outros - o relato verbal escrito, comentários de maior extensão, artigos, editoriais - que podem agregar sentido ou ressignificar essa captação mais imediata e rápida da olhadela. Essa olhadela é uma maneira de o leitor acercar-se dos fatos, informar-se, tendo a ilusão de inscrever-se no mundo, participar dele, mesmo que tudo isso muito superficialmente, pelas aparências do mundo, a partir daquilo que seu jornal diário veicula como representação e síntese dos eventos significativos, dentre tudo o que acontece (GOMES, 2008, p. 95).

O leitor, capturado pela manchete ou pela chamada, pode, por meio da indicação da página ou do caderno, ir direto para o texto de seu interesse, exercendo a leitura hipertextual. Porém, há leitores que preferem a leitura linear, folheando página a página, num movimento de passar os olhos pelas páginas, ora seguindo, 
ora detendo-se na leitura daquilo que lhe interessa.

Em sua composição, a capa de jornal se organiza na relação entre aspectos verbais e visuais, distribuindo as chamadas em colunas verticais e horizontais. A categoria topológica é a principal responsável pela articulação entre as linguagens verbal e visual. Essa organização topológica que se repete diariamente em um formato previsível gera um efeito de sentido de confiabilidade entre enunciador e enunciatário. Na primeira faixa horizontal, lê-se o nome do jornal. Nas colunas verticais, estão distribuídas as chamadas para as notícias. Fotos e charges, junto com as cores e formatos das fontes utilizadas, são os elementos visuais da capa. A montagem da capa revela escolhas: que informação é mais importante? Que fotografia usar? Que título atribuir a uma notícia? Todas essas escolhas definem a linha editorial do jornal, isto é, o ponto de vista que o jornal assume diante dos acontecimentos do mundo.

O estilo pode variar entre o mais sóbrio e o mais exuberante. $\mathrm{O}$ estilo mais sóbrio cria efeito de seriedade, ordem, equilíbrio. O estilo mais exuberante constrói efeitos de apelo, informalidade e descontração. O primeiro associa-se aos grandes temas nacionais e internacionais. $\mathrm{O}$ segundo, aos assuntos mais ligados à vida privada. Segundo Discini, nos jornais produzidos para as classes $\mathrm{A}$ e B, "jornais da imprensa dita séria", o enunciador é "eufemístico e fala baixo", em oposição a um enunciador "que grita, porque hiperbólico, nos jornais de imprensa dita sensacionalista" (DISCINI, 2003, p. 40).

Observemos as capas dos jornais $O$ Globo e Extra, veículos da mesma empresa destinados a públicos diferentes $(\mathrm{A} / \mathrm{B}$, o primeiro; $\mathrm{C} / \mathrm{D}$, o segundo), publicados na mesma data.

\section{Figura 3}

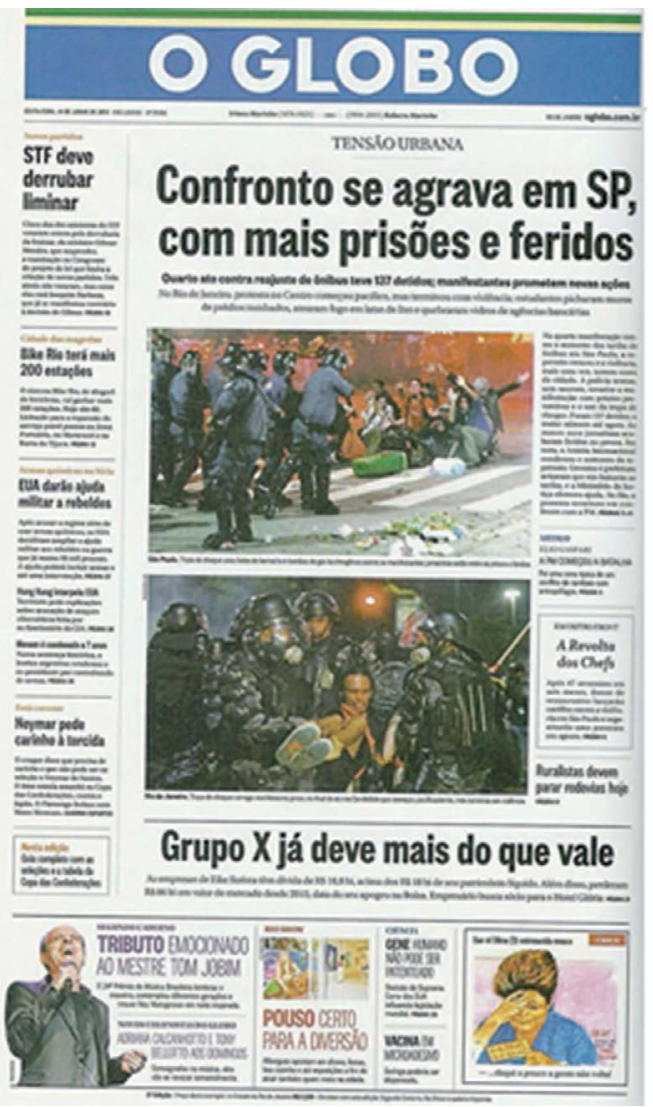

Fonte: O Globo. 14 jun 2013. Disponível em: http://acervo. oglobo.globo.com/consulta-ao-acervo/?navegaca oPorData=201020130614 Acessado em: 22 set 2014. 
Figura 4

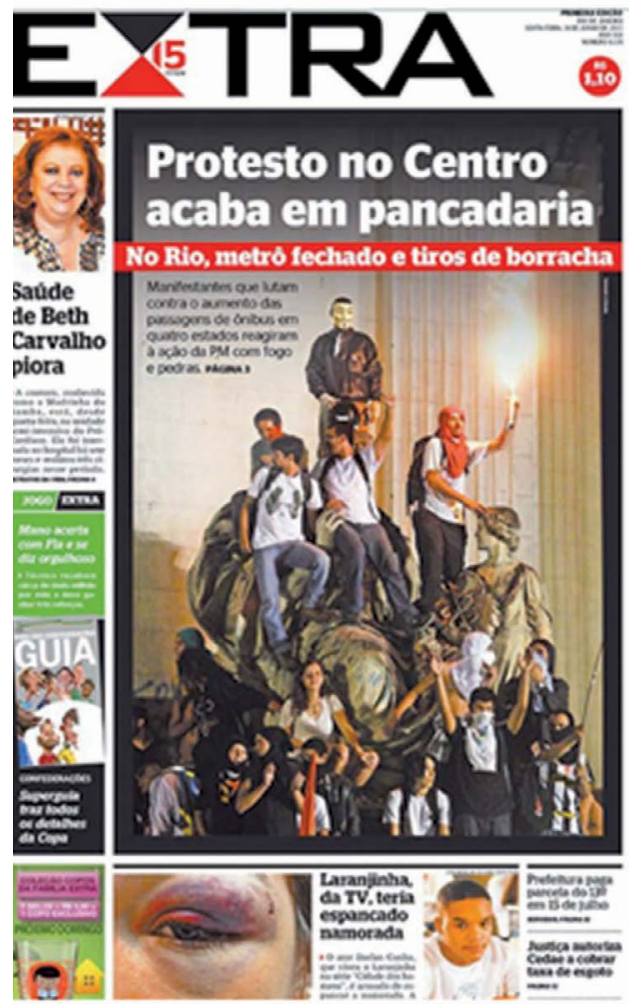

Fonte: Extra 14 jun 2013. Disponível em: http://extra.globo. com/capas-jornal-extra/14-06-2013-8685179.html Acessado em: 22 set 2014.

As características visuais de $O$ Globo são da ordem da contenção, a diagramação é equilibrada, com distribuição simétrica entre fotos e textos, recursos que falam de um enunciador discreto, que se dirige a um leitor de bom gosto, um leitor das meias medidas, contido também. No Extra, as fotos preenchem boa parte da capa e antecipam as chamadas verbais. Os recursos visuais são da ordem do exagero e da profusão, que aparecem no tamanho das fotos e das fontes gráficas utilizadas tanto na manchete como nas chamadas. Essas estratégias revelam um enunciador que recorre aos recursos hiperbólicos da expressão, fortes mecanismos de apelo à atenção do leitor. Os traços gráficos do plano da expressão, a contenção nas cores e traços, a organização das notícias em colunas divididas por linhas quase transparentes, nas capas de $O$ Globo, refletem o tipo de enunciador e enunciatário, fazendo com que este deseje entrar em conjunção com a leitura do jornal por se identificar imediatamente com seu modo de apresentação discreto, sóbrio e contido.

Os temas sensacionalistas são os que ficam em evidência no jornal Extra: futebol, violência, fofocas televisivas, voltados para o apelo popular, refletindo o enunciatário que busca nas páginas do veículo a informação mais cotidiana, de interesse mais imediato. Os temas escolhidos em $O$ Globo são abrangentes, gerais, relacionados ao coletivo, tratam de acontecimentos nacionais e internacionais e atendem à expectativa de um leitor antenado com questões de conjuntura econômica e política.

As escolhas temáticas, o uso de norma urbana de prestígio, o jogo de reiterações entre o verbal e o não verbal e a predominância da $3^{\underline{a}}$ pessoa são os principais recursos de conteúdo e expressão que constroem os efeitos de sentido de objetividade e imparcialidade e revelam um jornal que busca consagrar-se como autoridade, a partir da credibilidade que constitui seu perfil. 
A principal notícia do dia, a manchete, tem destaque nas capas, por meio da posição centralizada e das fontes em tamanho grande. Em O Globo, a manchete em negrito ressalta do fundo branco; no Extra, em cor branca, ela é sobreposta à foto, contrastando com a cor escura do fundo. O tempo verbal das chamadas geralmente está no presente do indicativo, ainda que se refiram a uma ação passada. O uso do tempo presente em lugar do pretérito é uma forma de estender a ação até o momento do agora, da produção do jornal e da sua leitura, dando-lhe status de atualidade, o que torna o fato mais próximo do leitor e caracteriza os gêneros da esfera jornalística, de modo geral.

Se os recursos de composição, observados aqui na diagramação da capa, já ressaltam o perfil de cada jornal, o estilo acentua a constituição semiótica de cada órgão de imprensa. O modo de dizer, tanto na forma escrita das notícias narradas quanto nas fotos e recursos visuais que as complementam, e a forma de comunicar, pelo comedimento ou pelo excesso, estabelecem as diferenças entre os dois jornais aqui destacados.

A fotografia no jornal contribui para a concretização de lugares, fatos e acontecimentos, pelo caráter icônico de imagens que reforçam a ilusão de realidade. A iconicidade "costuma estar associada à saturação de traços figurativos que busca aproximar a representação (feita por meio de uma pintura, uma fotografia, um texto verbal, etc) de uma imagem do mundo" (TEIXEIRA, 2001, p. 416). O procedimento de figurativização tenta recobrir ao máximo a realidade, quanto mais icônico, maior é o efeito de realidade obtido, pois "na fotografia a figuratividade remete a figuras do mundo natural, facilmente reconhecíveis, própria à iconicidade deste tipo de linguagem" (GOMES, 2008, p. 63).

Nas fotos das capas em análise, o láo exterior - foi inserido no aqui - espaço do enunciador - aproximando ainda mais o enunciatário do acontecimento. Diana Luz Pessoa de Barros destaca a importância das fotos, pois "o papel ancorador da fotografia [...] é assegurado pela crença ideológico-cultural no seu caráter de 'cópia do real"' (BARROS, 1990, p. 61). No jornal, a publicação da foto é também uma estratégia de argumentação fundamental, pois "funciona (...) como uma espécie de persuasão veridictória, uma garantia de fidelidade a um certo mundo real, concreto, dado. (...) [A fotografia] é tomada, por quem a observa, como documento, expressão de realidade, verdade, portanto" (TEIXEIRA, 2001, p. 416). O flagrante das manifestações feito pelas fotos concretiza o efeito de sentido de realidade e de verdade do texto jornalístico. Além do efeito de realidade, o enunciador, por meio dessa estratégia, simula estar em todos os lugares ao mesmo tempo, cobrindo todos os fatos.

Nas capas do Globo e do Extra, entretanto, as fotos da manifestação se diferenciam pelas tomadas, o foco, que confere maior ou menor particularização ao acontecimento. No Globo, duas 
fotos horizontalizadas documentam a brutalidade policial, acentuando o confronto entre manifestantes e forças institucionais. O jornal estabelece uma oposição entre desordem e preservação da ordem, mostra as forças em conflito, dando maior amplitude ao fato. No $E x$ tra, a foto única, verticalizada, dá ênfase aos manifestantes, elevando-os ao centro do acontecimento, valorizando o aspecto heroico da manifestação e diluindo o confronto. Imagens em contraposição, as duas fotos se associam aos sujeitos semióticos que as publicam: de um lado, a busca da objetividade, o interesse por um panorama geral e abrangente; de outro, a particularização da notícia, a escolha de um aspecto mais subjetivo do acontecimento. No primeiro caso, há harmonia e reiteração entre foto e manchete; no segundo, contraponto entre uma e outra. Se o visual tem maior força de apelo, a foto do Extra, com efeitos plásticos realçados pelos contrastes cromáticos e os efeitos de luz, cria efeito de subjetividade e realce da ação do grupo de manifestantes, enquanto as duas fotos do Globo pretendem reforçar o caráter documental da cobertura jornalística.

$\mathrm{Na}$ análise em sala de aula, não se pode abrir mão da relação entre fotografia e legenda, organização visual e notícias, recursos de projeção de pessoa, tempo e espaço e efeitos de subjetividade e objetividade. A construção de sentido na capa e no jornal de modo geral se dá justamente na articulação entre as imagens e os textos verbais, organizados por uma estratégia enunciativa que se manifesta visualmente na organização topológica do espaço, a partir da qual são estabelecidos os destaques e escolhidos os aspectos da realidade a noticiar.

\section{Conclusão}

Os exemplos sugerem uma estratégia de análise que começa no mapeamento de figuras e temas, elementos mais superficiais do discurso, passa pelas projeções de pessoa, tempo, espaço e as estratégias de interlocução com o enunciatário, que criam efeitos de aproximação e distanciamento com o enunciador, e termina na organização visual que integra sincreticamente todos os elementos. Cada texto, entretanto, solicita do leitor um olhar particular. Se o texto é uma $\mathrm{HQ}$, os elementos visuais são mais evidentes como condutores da narrativa. Se o jornal está em foco, as chamadas de primeira página exercem função primordial, logo se integrando à diagramação. Quando se examina um site da internet, também a visualidade, aliada aos movimentos solicitados ao internauta, pedem destaque na análise. Cada atividade de interpretação será diferente, reverente ao formato, às linguagens em relação e às possibilidades de sentido dos diferentes objetos semióticos. Uma teoria geral da significação, como a semiótica, propõe um modelo geral de análise, aplicável à leitura de qualquer texto, mas também enfatiza as particularidades dos diferentes códigos. 
A adoção de uma teoria não é uma questão de crença, mas de adesão, de escolha, de filiação à determinada matriz teórica. Entre crença e adesão existe a diferença conceitual que faz intervir na segunda a racionalidade. $\mathrm{Na}$ crença, tem-se a "atitude de quem se persuadiu de algo pelos caracteres de verdade que ali encontrou" (HOUAISS, 2001). Na adesão, não há aceitação, mas acordo, não há verdade, mas possibilidades que se oferecem, dentre as quais se escolhe uma, a partir de determinada análise. Essa diferença é fundamental e serve aqui para afirmar que o trabalho de pesquisa e suas aplicações origina-se na filiação, na adesão a alguma teoria e que sem a densidade de uma teoria bem assimilada e bem compreendida não há ensino que se sustente.

Em ensino de língua materna, costuma-se, muitas vezes, usar a opinião ou a crença como contraponto (quase sempre débil) do conhecimento. "Eu sinto que os alunos gostam", "Eu acho que assim eles aprendem mais rápido", "Eu tenho feito assim e os alunos gostam muito", "Eu acredito nesse tipo de exercício" - são recortes expressivos de um certo murmúrio ingênuo e difundido que associa ensino de língua portuguesa a alguma qualidade própria ou a alguma descoberta pessoal e intuitiva de um ou outro grande professor.

Experiência e vontade são efetivamente duas grandes forças que diferenciam atuações profissionais e podem, acrescentando entusiasmo ao trabalho, torná-lo mais bem sucedido. Um ensino de qualidade, no entanto, não se faz com a soma de boas atuações individuais, mas com uma mudança de concepção que, por sua vez, também só é possível com a criação de condições coletivas de engajamento e concentração de esforços. É nesse sentido que a adesão a uma teoria é importante: trata-se de uma forma de oferecer direção a um grupo que tem um objetivo comum definido.

Compreendida como matriz de produção de conhecimento, a teoria não é, necessariamente, terreno seco e pedregoso, árido, difícil de penetrar. Pode ser que se torne o ponto de partida de uma nova atitude, de um outro modo de olhar o mundo. Mesmo porque, trabalhar com a linguagem é estar sempre atento às paixões humanas, sejam elas feitas de papel, tinta, notas musicais ou qualquer outra linguagem.

É, aliás, com as paixões humanas que se pretende encerrar este texto. "Para aquele que fala e, em particular, para aquele cujo ofício é falar sobre o discurso, para o linguista, a língua pode ser um objeto de amor". E o amor pela língua é o amor pelo outro, pela diferença: "o amoroso das línguas é enamorado da alteridade" (HAGÈGE, 1998, p. 391 e 394).

Ser enamorado da língua materna é também apaixonar-se pela alteridade. Ou o que mais fazemos nós todos os dias, ensinando língua portuguesa, senão mostrar aos estudantes o mistério de existir na linguagem? Existir na linguagem é aproximar-se do outro a cada instante, para recebê-lo ou para rejeitá-lo. Pensar na linguagem, fazer 
dela objeto de reflexão e de trabalho, é não só compreender esse enamoramento da alteridade, mas vivê-lo em cada trabalho de pesquisa.

\section{Multimodal texts in portuguese class: reading methodology}

\section{Abstract}

The article presents a methodological proposal to address multimodal texts in Portuguese classes. It considers that multimodality is a way of producing content that comes from a post-industrial society and discusses the concept using Paris School of Semiotics as a base, which suggests a syncretic resolution to texts that operate with different languages. Undergoing an enunciative strategy, syncretic texts can't be addressed as a sum of different codes in interaction, but as products of enunciative operations that grant the idea of unity to diversity. It suggests ways to address such texts in school, with remarked examples.

Keywords: Syncretism, Multimodality, Enunciative strategy, Semiotics.

\section{Nota}

Lucia Teixeira (luciatso@gmail.com) é doutora em Linguística e Semiótica pela USP e atua no Programa de Pós-graduação em Estudos de Linguagem da Universidade Federal Fluminense; Sílvia Maria de Sousa (silviamsousa05@ gmail.com) é doutora em Letras pela UFF e professora do Programa de Pós-graduação em Estudos de Linguagem desta Universidade; Karla Faria (kcafaria@gmail.com ) é doutora em Estudos de Linguagem pela UFF. As autoras são pesquisadoras do SeDi-UFF (Grupo de Pesquisa em Semiótica e Discurso da UFF).

\section{Referências}

BAKHTIN, Mikhail. Estética da criação verbal. São Paulo: Martins Fontes, 2003.

CALVINO, Ítalo. As cidades invisíveis. São Paulo: Companhia das Letras,1990.

CARMO JR., José Roberto. Estratégias enunciativas na produção do texto publicitário verbo-visual. In: OLIVEIRA, Ana Claudia de; TEIXEIRA, Lucia (Orgs.). Linguagens na comunicação: desenvolvimentos de semiótica sincrética. São Paulo: Estação das Letras e Cores, 2009. p. 169-184.

CANCLINI, Néstor García. Leitores, espectadores e internautas. São Paulo: Iluminuras, 2008.

CLAUDEL, Paul. L'oeil écoute. Paris: Gallimard, 2003.

DISCINI, Norma. O estilo nos textos: história em quadrinhos, mídia e literatura. São Paulo: Contexto, 2003.

FARIA, Karla. Clique na notícia: análise semiótica de jornais on-line. Tese de doutorado. 196fl. Niterói: UFF, 2014.

FECHINE, Yvana. Contribuições para uma semiotização da montagem. In: OLIVEIRA, Ana Claudia de; TEIXEIRA, Lucia (Orgs.). Linguagens na comunicação: desenvolvimentos de semiótica sincrética. São Paulo: Estação das Letras e Cores, 2009. p. 323-369.

FLOCH, Jean-Marie. Une lecture de Tintin au Tibet. Paris: PUF, 2002.

. Semiótica plástica e linguagem publicitária: análise de um anúncio da campanha de lançamento do cigarro "News". In: OLIVEIRA, Ana Claudia de; TEIXEIRA, Lucia (Orgs.). Linguagens na comunicação: desenvolvimentos de semiótica sincrética. São Paulo: Estação das Letras e Cores, 2009. p. 145-167. 
FONTANILLE, Jacques. Práticas Semióticas. In: DINIZ, M. L. V. P.; PORTELA, J. C. (Orgs.). Semiótica e Midia. Bauru: UNESP/ FAAC, 2008.

FONTANILLE, Jacques. Semiótica do discurso. São Paulo: Contexto, 2007.

GOMES, Regina Souza. Relações entre linguagens no jornal: fotografia e narrativa verbal. Niterói: EdUFF, 2008.

GOMES, Regina Souza. O sincretismo no jornal. In: OLIVEIRA, Ana Claudia de; TEIXEIRA, Lucia (Orgs.). Linguagens na comunicação: desenvolvimentos de semiótica sincrética. São Paulo: Estação das Letras e Cores, 2009. p. 215-245.

GREIMAS, A. J.; COURTÉS, J. Dicionário de semiótica. São Paulo: Contexto, 2008. HAGÈGE, Claude. L'homme de paroles: contribution linguistique aux sciences humaines. Paris: Fayard, 1998.

HOUAISS, A. et al. Dicionário eletrônico Houaiss da língua portuguesa. Rio de Janeiro: Objetiva, 2001. Edição em CD-Rom, versão 1.0 .

JENKINS, Henry. Cultura da convergência. São Paulo: Aleph, 2009.

LÉVY, Pierre. As tecnologias da inteligência. Rio de Janeiro: Ed. 34, 1993.

KRESSE, G; VAN LEEUWEN, T. Reading images: the grammar of visual design. London: Routledge, 1996.

TEIXEIRA, Lucia. Relações entre o verbal e o não verbal: pressupostos teóricos. In: VII Caderno de Discussão do Centro de Pesquisas Sociossemióticas. São Paulo: CPS, 2001.

TEIXEIRA, Lucia. Para uma metodologia de análise de textos verbo-visuais. In: OLIVEIRA, Ana Claudia de; TEIXEIRA, Lucia (Orgs.). Linguagens na comunicação: desenvolvimentos de semiótica sincrética. São Paulo: Estação das Letras e Cores, 2009. p. 41-77.
TEIXEIRA, Lucia; CARMO JR., José Roberto do (Orgs.). Linguagens na cibercultura. São Paulo: Estação das Letras e Cores, 2013.

TEIXEIRA, Lucia; FARIA, Karla; SOUSA, Silvia Maria de. Projeto Apoema Português$7^{\mathrm{a}}$ ano. São Paulo: Editora do Brasil, 2013. 